\title{
Familiarity and shoal cohesion in fathead minnows (Pimephales promelas): implications for antipredator behaviour
}

\author{
Douglas P. Chivers, Grant E. Brown, and R. Jan F. Smith
}

\begin{abstract}
We exposed groups of four fathead minnows (Pimephales promelas) that were familiar to each other and had been taken from naturally occurring shoals, and groups of four fish unfamiliar to each other, taken from four separate shoals, to either chemical stimuli from pike or a model fish predator (northern pike, Esox lucius). In response to both chemical stimuli from pike and the pike model, minnows from familiar groups showed greater shoal cohesion than those from unfamiliar groups. Tighter shoal cohesion should result in a higher probability of surviving an encounter with a predator. Fish in familiar shoals also exhibited more dashing, a known antipredator response, than those in unfamiliar groups. In addition, groups of familiar fish showed less freezing behaviour than unfamiliar groups. In response to the model fish predator, familiar shoals exhibited a greater number of predator inspections, and the number of inspectors per inspection visit was greater, than those in unfamiliar groups. These results suggest that preferential shoaling with familiar conspecifics leads to an increase in cooperative antipredator behaviour and may thereby lower a minnow's risk of predation.
\end{abstract}

\begin{abstract}
Résumé : Nous avons exposé des groupes de quatre Têtes-de-boule (Pimephales promelas) familiers les uns avec les autres et provenant de bancs naturels et des groupes de poissons étrangers les uns aux autres (provenant de bancs différents) à des stimulus chimiques émis par des brochets ou à un modèle de poisson prédateur (le Grand Brochet, Esox lucius). En réaction aux deux types de stimulus, les ménés issus de bancs communs ont manifesté plus de cohésion dans leur groupe que les poissons étrangers les uns aux autres. Il est logique de penser que cette cohésion plus grande au sein du banc augmente la probabilité de survie lors d'une rencontre avec un prédateur. Les poissons provenant de bancs communs ont également utilisé plus de départs en flèche, une réaction anti-prédateurs fréquente, que les poissons provenant de bancs différents. De plus les groupes de poissons familiers les uns avec les autres ont manifesté moins d'attitudes « figées » que les poissons des groupes non familiers. En présence d'un modèle de prédateur, les poissons des bancs communs ont procédé à un plus grand nombre d'examens du prédateur, avec chaque fois un nombre plus grand d' « inspecteurs » que les poissons des groupes d'étrangers. Ces résultats indiquent que la formation de bancs avec des poissons déjà connus entraîne une augmentation des comportements anti-prédateurs concertés et peut donc diminuer les risques de prédation.

[Traduit par la Rédaction]
\end{abstract}

\section{Introduction}

The ability to discriminate familiar from unfamiliar conspecifics has been demonstrated in many fish species, including bluegill sunfish, Lepomis macrochirus (Brown and Colgan 1986), paradise fish, Macropodus opercularis (Miklosi et al. 1992), threespine stickleback, Gasterosteus aculeatus (Van Havre and FitzGerald 1988), and fathead minnows, Pimephales promelas (Brown and Smith 1994). Fathead minnows originally caught in the same natural shoal but kept separate for over 2 months are still more attracted to their former shoal mates than to fish from other shoals, demonstrating longterm recognition abilities (Brown and Smith 1994).

Van Havre and FitzGerald (1988) suggested that preferen-

Received October 7, 1994. Accepted February 22, 1995.

D.P. Chivers, G.E. Brown, and R.J.F. Smith. Department of Biology, 112 Science Place, University of Saskatchewan,

Saskatoon, SK S7N 5E2, Canada. tially shoaling with familiar individuals may be favoured if shoaling benefits are higher in familiar shoals. They suggest that under risk of predation, shoals of individuals familiar to each other should form more quickly and more cohesively than if group members are unfamiliar to each other. Other antipredator adaptations may also lead to preferential shoaling with familiar conspecifics. Predator inspection behaviour (reviewed by Pitcher 1992), where an individual or small group of individuals approach a predator, pause, and swim away, has been shown to have antipredator benefits. Benefits associated with predator recognition are inferred from studies demonstrating that the rate of inspection decreases for nonpredatory fishes (Csányi 1985) or for objects that do not look like predators (Magurran and Girling 1986). Other studies have shown that inspection behaviour may enable fish to move away from an incipient attack (Magurran and Pitcher 1987), distinguish between a hungry and a satiated predator (Licht 1989), or inhibit the predator from attacking (Magurran 1990; Godin and Davis 1995). 
In this study we investigate differences in shoaling behaviour between groups of fathead minnows from naturally occurring shoals and groups of unfamiliar conspecifics in response to either chemical or visual stimuli from a potential predator. In the first experiment we exposed groups of four shoal mates and groups of four unfamiliar fish to chemical stimuli from pike, Esox lucius, testing the hypothesis that groups of minnows familiar to each other will exhibit greater shoal cohesion than unfamiliar groups. For fathead minnows, greater shoal cohesion is correlated with longer survival time during interactions with pike (Mathis and Smith 1993).

We also compared the incidence of dashing and freezing, two known antipredator behaviours, between groups of familiar and unfamiliar minnows. Dashing, a rapid burst of apparently disoriented swimming, may take the minnow away from the immediate vicinity of the predator, or may prevent the predator from locking its sights onto the prey (Lawrence and Smith 1989; Mathis et al. 1993). Dashing, like skittering in European minnows, Phoxinus phoxinus (Pitcher and Parrish 1993), may also act as a visual alarm signal to warn nearby conspecifics of danger. If familiar fish are more likely to be in close proximity to each other, visual confusion caused by dashing may be enhanced in shoals of familiar fish. In addition, the danger associated with attracting a predator's attention during dashing may be less for familiar fish than for unfamiliar fish if familiar fish are more likely to be in close proximity. Therefore, we hypothesized that familiar individuals from naturally occurring shoals would be more likely to exhibit dashing than individuals from unfamiliar shoals. In contrast, we hypothesized that freezing, where a fish drops to the bottom and remains immobile for a minimum of $30 \mathrm{~s}$ (Chivers and Smith 1994a; 1995), would occur more frequently in individuals within unfamiliar shoals. If an individual from an unfamiliar shoal is not in close proximity to its shoal mates, its most effective antipredator strategy should be that of remaining motionless and escaping detection rather than dashing to elicit cooperative antipredator behaviour from its shoal mates. Magurran and Pitcher (1987) demonstrated that European minnows which have been separated from their shoal during an attack by a predator often hide individually instead of attempting to rejoin their shoal.

In a second experiment we exposed groups of four familiar and four unfamiliar fish to a model predatory fish and recorded shoal cohesion, dashing, and freezing. In addition, we counted the inspection visits and the number of individuals participating in each inspection visit. Because tighter shoaling reduces the probability of being captured by a predator (Mathis and Smith 1993), and we predicted that familiar groups would exhibit tighter shoaling, groups of familiar fish may be at a lower risk of predation. As a result we hypothesized that groups of familiar fish would perform more inspection behaviour than groups of unfamiliar fish. The results of our study are discussed in the context of the potential antipredator benefits of shoaling with familiar conspecifics.

\section{Methods}

\section{Experiment 1}

Fish collection and maintenance

We collected 6 discrete shoals of fathead minnows from Pike Lake, an oxbow lake of the South Saskatchewan River in south-central Saskatchewan. Fish from each shoal were col- lected using a beach seine along a 3-m section of shoreline. Different shoals were collected not less than $200 \mathrm{~m}$ apart. We divided each shoal into 2 equal subgroups and maintained the minnows in the laboratory in 12 identical $37-\mathrm{L}$ aquaria at approximately $20^{\circ} \mathrm{C}$ on a $12 \mathrm{~h}$ light : $12 \mathrm{~h}$ dark photoperiod, feeding them once daily with Nutrafin Goldfish Food.

Fathead minnows and northern pike co-occur in Pike Lake. Mathis et al. (1993) have demonstrated that minnows from Pike Lake will exhibit a stereotypic fright reaction to the chemical stimuli from a pike, regardless of the diet of the pike.

\section{Preparation of the pike stimulus}

We fed one pike (fork length $18 \mathrm{~cm}$ ) with a single swordtail (Xiphophorus helleri, approximately $3.0-4.0 \mathrm{~mL}$, measured by volumetric displacement in water) once every 5 days for three consecutive feedings before collecting the stimulus. Swordtails were used because they lack alarm pheromone (Mathis and Smith 1993), which is known to elicit a stereotypic fright response in minnows detecting it in the diet of a predator (Brown et al. 1995). Twelve hours after the last feeding we placed the pike in a clear-plastic stimulus-collection chamber $(26 \times 8 \times 8 \mathrm{~cm})$ containing $1200 \mathrm{~mL}$ of dechlorinated tap water. We aerated the chamber but did not filter the water. Twenty-four hours later we removed the pike from the chamber and siphoned the fecal matter out of the chamber. We pipetted the remaining stimulus water into plastic bags and froze it at approximately $-20^{\circ} \mathrm{C}$.

\section{Testing protocol}

Observation tanks $(37 \mathrm{~L} ; 50 \times 30 \times 25 \mathrm{~cm})$ containing approximately $3 \mathrm{~cm}$ of silica sand substrate were filled with dechlorinated tap water and aerated with a single airstone located at the back of each tank. A plastic tube to introduce the stimulus water was attached to the air line. Each tank contained 4 circular clear-plastic acclimation chambers $(21 \mathrm{~cm}$ long, $11 \mathrm{~cm}$ in diameter). Each acclimation chamber was perforated to allow water exchange but prevented fish from escaping. The acclimation chambers, which were arranged so that each was in one corner of the aquarium, were attached to a pulley so that they could be removed simultaneously by the observer stationed approximately $1 \mathrm{~m}$ in front of the tanks.

We arbitrarily selected groups of four familiar fish (four shoal mates from the same holding tank, each captured individually) or four unfamiliar fish (one fish from each of four different shoals). We measured each fish and placed one fish in each acclimation chamber. In total, 12 groups each were tested in the familiar (mean fork length $4.21 \pm 0.76 \mathrm{~cm}$ ) and unfamiliar groups (mean fork length $4.19 \pm 0.84 \mathrm{~cm}$ ). Fish in the familiar and unfamiliar groups were matched for size. Each fish was tested only once.

After the fish had acclimated for $2 \mathrm{~h}$, we injected $20 \mathrm{~mL}$ of pike stimulus (= pike odour; Chivers and Smith 1993) into the tank and immediately removed the acclimation chambers to allow the minnows to interact. Acclimation chambers were removed slowly (over a period of 8-10 s) to minimize any disturbance. The short acclimation time minimized the possibility that unfamiliar fish would become familiar with each other. The removal of the acclimation chambers may have caused some disturbance, perhaps resulting in a complex stimulus (disturbance component plus the chemical cue from a known predator). Comparisons between familiar and unfamiliar groups in the absence of a predator stimulus were 
not conducted. Even if a significant difference due to the disturbance component of the stimulus was observed between familiar and unfamiliar groups, this difference would function to lower the risk of predation for the minnows in the more cohesive group.

For $10 \mathrm{~min}$ following the removal of the barriers we recorded an index of shoaling at intervals of $15 \mathrm{~s}$, as per Mathis and Smith (1993). The shoaling index ranged from 1 to 4 as follows: (1) no minnow within one body length of any other, (2) two minnows within one body length of each other, and each of the other two more than one body length from their nearest neighbour, (3) three minnows within one body length of another minnow, or two groups of two minnows within one body length of each other but the groups separated by at least one body length, and (4) a single group with all four minnows within one body length of another minnow. Throughout this paper we do not differentiate schooling (a synchronized and polarized group) from the broader category of shoaling (Pitcher 1983); generally, however, the shoaling minnows were swimming in a polarized and synchronized group. In addition to the index of shoaling, we recorded the presence or absence of two additional components of an antipredator response in fathead minnows: (1) dashing, which is very rapid, apparently disoriented swimming, and (2) freezing, which is the cessation of movement, where the fish drops to the bottom of the tank and remains immobile for a minimum of $30 \mathrm{~s}$. Since individual minnows were difficult to identify, we recorded that a group had exhibited dashing or freezing if this activity was performed by any one of the four minnows in the group.

We used a Wilcoxon-Mann-Whitney test (Siegel and Castellan 1988) to compare the shoaling indices between the familiar and unfamiliar groups. Data for presence versus absence of dashing and freezing were analyzed using Fisher's exact probability test (Siegel and Castellan 1988). As we predicted that under the risk of predation, shoals of familiar individuals would form more quickly and more cohesively than if group members were unfamiliar to each other, we employed one-tailed statistical tests with $\alpha=0.05$.

\section{Experiment 2}

\section{Fish collection and maintenance}

Fish were collected and housed as in experiment 1 .

\section{Testing protocol}

Observation tanks $(450 \mathrm{~L} ; 180 \times 50 \times 50 \mathrm{~cm})$ containing a shallow layer of silica sand were filled with dechlorinated tap water and aerated with a single airstone located at the back of each tank. We positioned the 4 plastic acclimation chambers used in experiment 1 at one end of each tank. A fish lure, $18 \mathrm{~cm}$ in length, that resembled a pike was used as a model predator. The model was buried in the sand at the opposite end of the tank from the acclimation chambers and was covered with one half of a clay flower pot, so that when presented, the model appeared to come from inside the pot. The predator model was attached to a monofilament fishing line that stretched the length of the tank. A second monofilament fishing line was attached to the model and a pulley so that an observer could advance the predator model without approaching the tank.

As in the previous experiment, we arbitrarily selected groups of four familiar fish (each captured individually) or four unfamiliar fish, measured them, and placed one fish into each of the 4 acclimation chambers. We tested 12 familiar groups (mean fork length $3.98 \pm 0.58 \mathrm{~cm}$ ) and 12 unfamiliar groups (mean fork length $3.96 \pm 0.80 \mathrm{~cm}$ ). Fish in familiar and unfamiliar groups were matched for size. Each fish was tested only once. The fish tested in experiment 2 were not the individuals tested in experiment 1 .

After the fish had acclimated for $2 \mathrm{~h}$ we slowly removed the acclimation chambers, as in experiment 1 , to allow the fish to interact. As in experiment 1 , in addition to the predator stimulus, there may have been disturbance associated with the removal of the acclimation chambers. Two minutes later we started to advance the predator model toward the end of the tank containing the acclimation chambers. We pulled the model for a distance of $25 \mathrm{~cm}$ over a 10 -s period and kept it still for $1 \mathrm{~min}$. We repeated this 6 times. This method of presentation resembles the way in which pike typically stalk their prey (Webb and Skadsen 1980; personal observation). Once the model had been pulled from its concealed position we began recording the shoaling index every $15 \mathrm{~s}$ as in experiment 1 . The 2 -min delay between removing the acclimation chambers and starting data collection minimized any disturbance caused by the removal of the acclimation chambers. We also recorded whether any minnow in the shoal exhibited dashing or freezing. In addition, we counted the inspection visits and the number of individuals participating in each inspection visit. An inspection visit occurred when an individual minnow or group of minnows moved to within $36 \mathrm{~cm}$ of the predator model, then paused and swam away from it. We chose $36 \mathrm{~cm}$ as the minimum distance over which a minnow would have to approach the model because it is equal to two predator body lengths, a distance just outside the range from where esocids normally attack (Webb and Skadsen 1980).

We used the Wilcoxon-Mann-Whitney test to compare the shoaling indices and the numbers of inspection visits of familiar versus unfamiliar groups. To examine the average group size a minnow will experience during an inspection visit, we calculated the geometric mean (Sokal and Rolf 1981) and compared familiar and unfamiliar groups using the Wilcoxon-Mann - Whitney test. The prevalence of dashing and freezing was analyzed as in experiment 1.

\section{Results}

\section{Experiment 1}

Following exposure to chemical stimuli from pike, both the familiar and unfamiliar groups exhibited shoaling behaviour. However, the intensity of shoaling in groups of familiar minnows was significantly greater than in groups of unfamiliar minnows ( $W_{x}=84, m=12 ; n=12 ; P<0.001$; Fig. 1$)$. In addition, groups of familiar minnows also showed a significantly greater frequency of dashing ( 12 vs. 8; Fisher's exact probability, $P=0.047$ ) and a significantly lower frequency of freezing ( 1 vs. 6; Fisher's exact probability, $P=$ $0.034)$ than fish in unfamiliar groups.

\section{Experiment 2}

The results of experiment 2 concur with those of experiment 1 . In response to the predator model the familiar groups showed a significantly greater degree of shoaling than the unfamiliar 
Fig. 1. Mean ( \pm 1 SE) shoaling index for familiar shoal mates and unfamiliar groups in response to pike odour. A larger mean shoaling index is indicative of greater shoal cohesion.

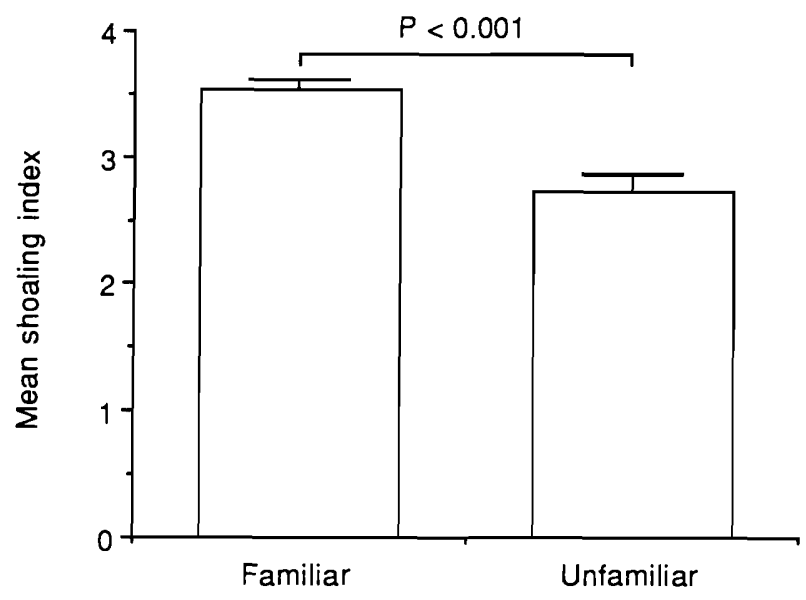

Fig. 2. Mean ( $\pm 1 \mathrm{SE}$ ) shoaling index for familiar shoal mates and unfamiliar groups in response to the model fish predator.

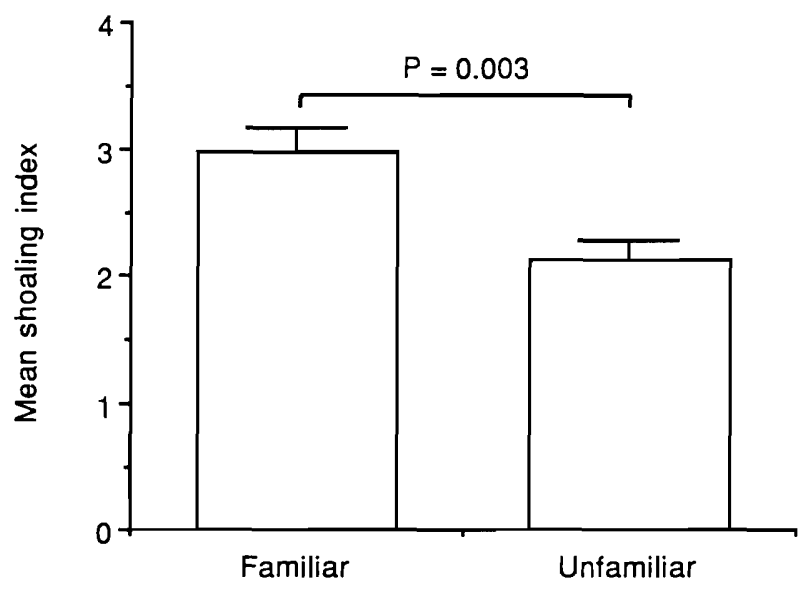

groups $\left(W_{x}=102.5, m=12 ; n=12 ; P=0.003\right.$; Fig. 2$)$. In addition, familiar groups also exhibited a significantly greater frequency of dashing (11 vs. 3; Fisher's exact probability, $P<0.001)$ and a significantly lower frequency of freezing (4 vs. 9; Fisher's exact probability, $P=0.049$ ) than unfamiliar groups. Familiar groups exhibited a significantly greater number of inspection visits $\left(W_{x}=111, m=12\right.$; $n=12 ; P=0.013$; Fig. 3 ) than unfamiliar groups. As well, individuals within familiar groups inspected with a significantly greater number of conspecifics than those in unfamiliar groups $\left(W_{x}=118, m=12 ; n=12 ; P=0.032\right.$; Fig. 4$)$.

\section{Discussion}

The results of this study clearly demonstrate a significant effect of familiarity on shoaling and other aspects of antipredator behaviour. In response to both pike odour and a model fish predator (and any disturbance component), groups of familiar shoal mates show a higher degree of shoal cohesion than unfamiliar groups. This difference in shoal cohesion should increase the probability that familiar individuals will
Fig. 3. Mean $( \pm 1 \mathrm{SE})$ number of inspection visits performed by familiar shoal mates and unfamiliar groups in response to the model fish predator.

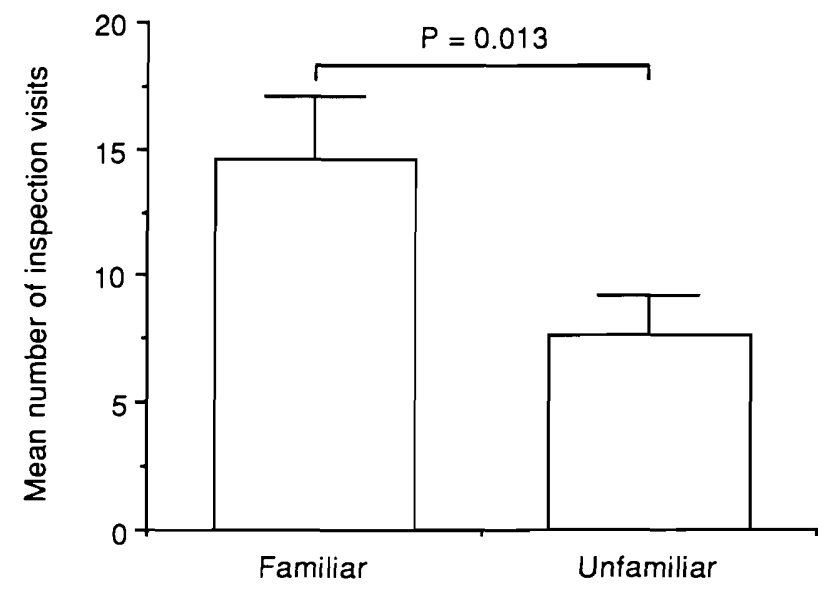

Fig. 4. Mean ( $\pm 1 \mathrm{SE}$ ) number of inspectors per inspection visit for familiar shoal mates and unfamiliar groups in response to the model fish predator.

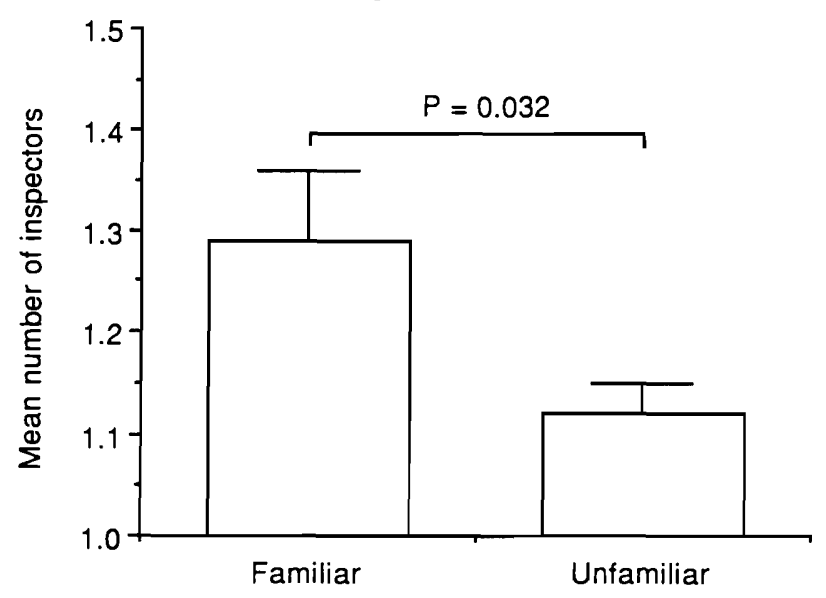

survive an encounter with a predator. Mathis and Smith (1993) demonstrated that greater shoal cohesion is correlated with a longer survival time for fathead minnows during interactions with northern pike.

It is possible that the differences in the incidence of shoal cohesion, dashing and freezing, and possibly predator inspection visits may be due in part to the disturbance caused by removing the acclimation chambers. In light of this, we cannot attribute the observed responses solely to the chemical or visual stimuli from the predators. Nevertheless, for a number of reasons we can speculate on the role of familiarity in antipredator behaviours. Dashing and freezing have been established as stereotypic antipredator behaviours in cyprinid fishes (Lawrence and Smith 1989; Mathis and Smith 1993; Mathis et al. 1993; Chivers and Smith 1994a, 1994b). In addition, shoaling and predator inspection visits have also been shown to increase protection from predation, and their frequency has been shown to increase under the risk of predation (Magurran 1990; Magurran and Pitcher 1987). We can therefore interpret these data in the context of an antipredator response.

In light of the difference in shoal cohesion, the differences 
in the occurrence of dashing and freezing between familiar and unfamiliar groups can be readily explained. In general, a minnow in a familiar shoal will be in closer proximity to its shoal mates. By dashing, an individual minnow within a cohesive group can enhance the confusion effect. Dashing should also warn other members of the shoal, which may lead to the initiation of group evasion behaviours. Generally, minnows in a group of unfamiliar individuals will not be in as close proximity to its shoal mates as those in familiar groups. Dashing by individuals in an unfamiliar group may attract the attention of the predator, yet cause little confusion because the individuals are dispersed. As a result, minnows in groups of unfamiliar individuals may benefit more by freezing and attempting to avoid detection by the predator than by dashing and trying to recruit shoal mates for the purpose of confusing a predator and evading it through being in a group. European minnows that have been separated from their shoal during a predator attack often hide individually among stones as a last resort (Magurran and Pitcher 1987).

Considerable evidence suggests that predator inspection behaviour is risky. For example, George (1960) and Magurran and Seghers (1990) demonstrated that inspecting mosquitofish (Gambusia affinis) and guppies (Poecilia reticulata) avoid the predator's attack cone. Nevertheless, inspection behaviour is beneficial for assessing the predator (Pitcher 1992). In this study, minnows from familiar shoals inspected a model fish predator more often than minnows from unfamiliar shoals. Furthermore, the average group size experienced by a minnow during an inspection visit was larger for familiar shoals than for unfamiliar groups. Because the familiar shoals in our study were shoaling more cohesively and inspecting with a greater number of shoal mates, they were likely to be at a lower risk of being captured. The greater number of individuals inspecting in the familiar groups may be the result of cooperation between shoal mates or a by-product of greater shoal cohesion. Nevertheless, inspecting in a larger group confers several advantages on each individual in the inspecting group. The greater the number of inspectors the lower the probability that any one individual will be captured and the greater the confusion effect if an attack is initiated. Benefits derived from inspecting may be further enhanced if larger groups of inspectors approach predators more closely (Pitcher et al. 1986). Finally, a larger group of inspectors may decrease the likelihood that the predator will attack (Magurran 1990).

Studies of European minnows (Naish et al. 1993) and fathead minnows (Wisenden et al. 1995) suggest that shoals may continually split and reform over extended periods. However, it remains unclear whether small groups within larger shoals remain together when shoals split. Brown and Smith (1994) demonstrated that chemical cues alone are sufficient to allow fathead minnows to discriminate familiar shoal mates from unfamiliar conspecifics, and that such preferential shoaling remains even after the shoal mates have been separated for more than 2 months. These results suggest that even if familiar individuals are separated, they can probably rejoin familiar individuals after an extended period. The long-term recognition of shoal mates may bring the potential for reciprocity. If dashing acts as a visual alarm signal, but puts the sender at risk of capture, minnows from familiar shoals may signal to each other on the basis of previous experience of the cooperativeness of their shoal mates. In contrast, minnows from unfamiliar groups will have had no prior experience with members of their group and would not know whether the other minnows are likely to reciprocate. Therefore, individuals from unfamiliar shoals should be less likely to perform dashing than minnows in familiar shoals. Individuals within familiar shoals may also exhibit more dashing behaviour if they are related to their shoal mates, since this may increase inclusive fitness (Wilson 1987) potential.

Our results show that the antipredator behaviours of groups of familiar shoal mates differ from those of unfamiliar groups. The apparent benefits of shoaling with familiar individuals should be a strong selective force for long-term retention of recognition of familiar fish, especially since minnow shoals may continually break up and reform over relatively long periods of time (Naish et al. 1993).

\section{Acknowledgements}

We thank Brian Wisenden for helping to collect fish and for providing helpful suggestions on an earlier version of the manuscript. This study was supported by the Natural Sciences and Engineering Research Council of Canada and the University of Saskatchewan.

\section{References}

Brown, G.E., and Smith, R.J.F. 1994. Fathead minnows use chemical cues to discriminate shoalmates from unfamiliar conspecifics. J. Chem. Ecol. 20: 3051-3061.

Brown, G.E., Chivers, D.P., and Smith, R.J.F. 1995. Localized defecation by pike: a response to labelling by cyprinid alarm pheromone? Behav. Ecol. Sociobiol. 36: 105-110.

Brown, J.A., and Colgan, P.W. 1986. Individual and species recognition in centrarchid fishes: evidence and hypotheses. Behav. Ecol. Sociobiol. 19: 373-379.

Chivers, D.P., and Smith, R.J.F. 1993. The role of olfaction in chemosensory-based predator recognition in the fathead minnows, Pimephales promelas. J. Chem. Ecol. 19: 623-633.

Chivers, D.P., and Smith, R.J.F. 1994a. The role of experience and chemical alarm signalling in predator recognition by fathead minnows, Pimephales promelas. J. Fish Biol. 44: 273-285.

Chivers, D.P., and Smith, R.J.F. 1994b. Fathead minnow, Pimephales promelas, acquire predator recognition when alarm substance is associated with the sight of unfamiliar fish. Anim. Behav. 48: 597-605.

Chivers, D.P., and Smith, R.J.F. 1995. Fathead minnows, Pimephales promelas, learn to recognize chemical stimuli from high risk habitats by the presence of alarm substance. Behav. Ecol. 6: $155-158$.

Csányi, V. 1985. Ethological analysis of predator recognition by the paradise fish, Macropodus opercularis L. I. Recognition and learning of predators. Behaviour, 92: 227-240.

George, C.J.W. 1960. Behavioural interactions of the pickerel and the mosquitofish. Ph.D. thesis, Harvard University, Cambridge, Mass.

Godin, J.-G.J., and Davis, S.A. 1995. Who dares, benefits: predator approach behaviour in the guppy (Poecilia reticulata) deters predator pursuit. Proc. R. Soc. Lond. B Biol. Sci. In press.

Lawrence, B.J., and Smith, R.J.F. 1989. Behavioural response of solitary fathead minnows, Pimephales promelas, to alarm substance. J. Chem. Ecol. 15: 209-219.

Licht, T. 1989. Discrimination between hungry and satiated preda- 
tors: the response of guppies from high and low predation sites. Ethology, 82: 238-243.

Magurran, A.E. 1990. The adaptive significance of schooling as an anti-predator defence in fish. Ann. Zool. Fenn. 27: 51-66.

Magurran, A.E., and Girling, S. 1986. Predator recognition and response habituation in shoaling minnows. Anim. Behav. 34: 510-518.

Magurran, A.E., and Pitcher, T.J. 1987. Provenance, shoal size and the sociobiology of predator evasion behaviour in minnow shoals. Proc. R. Soc. Lond. B Biol. Sci. 229: 439-465.

Magurran, A.E., and Seghers, B. 1990. Population differences in predator recognition and attack cone avoidance in the guppy. Anim. Behav. 40: 443-452.

Mathis, A., and Smith, R.J.F. 1993. Chemical alarm signals increase the survival time of fathead minnows (Pimephales promelas) during encounters with northern pike (Esox lucius). Behav. Ecol. 4: 260-265.

Mathis, A., Chivers, D.P., and Smith, R.J.F. 1993. Population differences in responses of fathead minnows (Pimephales promelas) to visual and chemical stimuli from predators. Ethology, 93: $31-40$.

Miklosi, A., Haller, J., and Csányi, V. 1992. Different duration of memory for conspecific and heterospecific fish in the paradise fish (Macropodus opercularis L.) Ethology, 90: 29-36.

Naish, K.-A., Carvalho, G.R., and Pitcher, T.J. 1993. The genetic structure and microdistribution of shoals of Phoxinus phoxinus, the European minnow. J. Fish Biol. 43(Suppl. A): 75-89.
Pitcher, T. 1983. Heuristic definitions of shoaling behaviour. Anim. Behav. 31: 611-613.

Pitcher, T. 1992. Who dares, wins: the function and evolution of predator inspection behaviour in shoaling fish. Neth. J. Zool. 42: $371-391$.

Pitcher, T.J., and Parrish, J. 1993. The function of shoaling behaviour. In The behaviour of teleost fishes. 2nd ed. Edited by T.J. Pitcher. Chapmann and Hall, London. pp. 363-439.

Pitcher, T.J., Magurran, A.E., and Allan, J.R. 1986. Size segregative behaviour in minnow shoals. J. Fish Biol. 29: 83-95.

Siegel, S., and Castellan, N.J. 1988. Nonparametric statistics for the behavioral sciences. McGraw-Hill, New York.

Sokal, P.R., and Rohlf, F.J. 1981. Biometry. W.H. Freeman and Co., New York.

Van Havre, N., and FitzGerald, G.J. 1988. Shoaling and kin recognition in the threespine stickleback (Gasterosteus aculeatus L.) Biol. Behav. 13: 190-201.

Webb, P.W., and Skadsen, J.M. 1980. Strike tactics of Esox. Can. J. Zool. 58: $1462-1469$.

Wilson, E.O. 1987. Kin recognition. An introductory synopsis. In Kin recognition in animals. Edited by D.J.C. Fletcher and C.D. Mitchner. John Wiley and Sons. Chichester, U.K. pp. 7-18.

Wisenden, B.D., Chivers, D.P., Brown, G.E., and Smith, R.J.F. 1995. The role of experience in risk assessment: avoidance of areas chemically labelled with fathead minnow alarm pheromone by conspecifics and heterospecifics. Ecoscience. In press. 